\title{
Fuel Conditioning Facility Electrorefiner Process Model
}

\section{Separations Science and Technology Symposium}

DeeEarl Vaden

\author{
October 2005
}

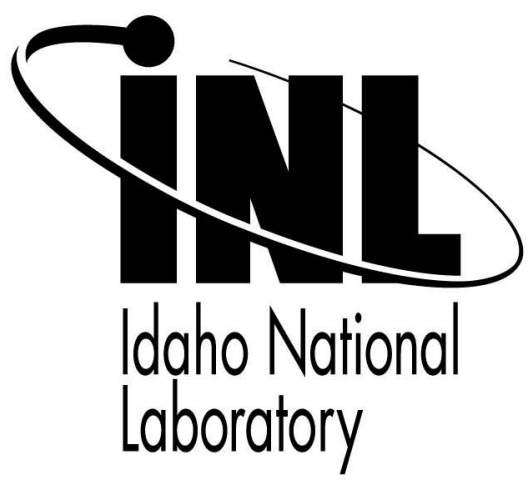

This is a preprint of a paper intended for publication in a journal or proceedings. Since changes may be made before publication, this preprint should not be cited or reproduced without permission of the author. This document was prepared as an account of work sponsored by an agency of the United States Government. Neither the United States Government nor any agency thereof, or any of their employees, makes any warranty, expressed or implied, or assumes any legal liability or responsibility for any third party's use, or the results of such use, of any information, apparatus, product or process disclosed in this report, or represents that its use by such third party would not infringe privately owned rights. The views expressed in this paper are not necessarily those of the United States Government or the sponsoring agency. 


\title{
Fuel Conditioning Facility Electrorefiner Process Model
}

\author{
DeeEarl Vaden ${ }^{*}$ \\ Fuel Cycle Programs Division, Idaho National Laboratory, Idaho Falls, Idaho, USA
}

\begin{abstract}
The Fuel Conditioning Facility at the Idaho National Laboratory processes spent nuclear fuel from the Experimental Breeder Reactor II using electro-metallurgical treatment. To process fuel without waiting for periodic sample analyses to assess process conditions, an electrorefiner process model predicts the composition of the electrorefiner inventory and effluent streams. For the chemical equilibrium portion of the model, the two common methods for solving chemical equilibrium problems, stoichiometric and non-stoichiometric, were investigated. In conclusion, the stoichiometric method produced equilibrium compositions close to the measured results whereas the non-stoichiometric method did not.
\end{abstract}

Key Words: Pyrochemical processing; Electrorefiner; Chemical equilibrium; stoichiometric.

\footnotetext{
* Correspondence: D. Vaden, Idaho National Laboratory, P.O. Box 1625, Idaho Falls, ID 83415-6180;

E-mail: dee.vaden@inl.gov
} 


\section{INTRODUCTION}

Electro-metallurgical treatment of spent nuclear fuel is performed in the Fuel Conditioning Facility (FCF) at the Idaho National Laboratory (INL) as part of the Advanced Fuel Cycle Initiative (AFCI). The process treats spent fuel from the Experimental Breeder Reactor II (EBR-II) by separating uranium from the fission products and structural materials (cesium, sodium, steel cladding, etc.) in a vessel called an electrorefiner (ER) ${ }^{[1,2]}$. Having process knowledge of the ER inventory prior to sample analysis is essential for timely operations and material accountability. A way to obtain this knowledge is to predict the mass and composition in the ER inventory and effluent streams without waiting for sampling and analysis, which are time consuming for FCF and the Analytical Laboratory. To serve this purpose, an ER process model was developed to predict the mass and composition of the ER inventory and its effluent streams using multi-component, multi-phase chemical equilibrium and electro-chemical transport from the anode(s) to the cathode(s). For the chemical equilibrium portion of the model, the author investigated two common approaches, defined as stoichiometric and non-stoichiometric ${ }^{[3]}$, for determining chemical equilibrium compositions. The nonstoichiometric method minimizes the total Gibbs free energy by adjusting the quantity of the species directly while satisfying mass-balance constraints. The stoichiometric method adjusts the progress or extent of each chemical reaction to minimize the total Gibbs free energy in the system.

This paper briefly describes the Mark-IV electrorefiner, the loading of chemicals into the ER to establish initial conditions for processing spent fuel, the comparison of the results from the two 
chemical equilibrium methods to ER sample analyses, and conclusions. This is not a major investigation of the vast field of chemical equilibrium, but an answer to the question, "Given the choice between the stoichiometric or non-stoichiometric method, which produces an equilibrium composition in close agreement with the measured results obtained after the initial loading of chemicals into the Mark-IV electrorefiner?"

\section{EXPERIMENTAL}

\section{Apparatus}

The Mark-IV electrorefiner, a steel vessel one-meter tall with a one meter inside diameter maintained at $500 \mathrm{C}$, contains a salt bath and a cadmium bath (see Figure 1). Initially the system contained 4601 moles $(195 \mathrm{~kg})$ of lithium chloride $(\mathrm{LiCl}), 3159$ moles $(236 \mathrm{~kg})$ of potassium chloride (KCl), and 4720 moles $(531 \mathrm{~kg}$ ) of cadmium $(\mathrm{Cd})$ in the cadmium bath.

For the experiment, 84.08 moles $(20 \mathrm{~kg})$ of uranium metal was loaded into porous steel baskets and immersed into the salt bath followed by 126 moles $(23 \mathrm{~kg})$ of cadmium chloride $\left(\mathrm{CdCl}_{2}\right)$ to chemically oxidize the uranium in the baskets to uranium chloride via the chemical reaction shown in equation 1.

$$
3 \mathrm{CdCl}_{2}+2 \mathrm{U} \leftrightarrow 3 \mathrm{Cd}+2 \mathrm{UCl}_{3}
$$

At $773 \mathrm{~K}$, the Gibbs free energies of formation for the $\mathrm{CdCl}_{2}$ and $\mathrm{UCl}_{3}$ species are -64.62 and $-165.6 \mathrm{kcal} /$ mole, respectively ${ }^{[4]}$. The elements uranium (U) and cadmium $(\mathrm{Cd})$ have no free energy of formation. The Gibbs free energy of the chemical reaction in equation 1 is $-3(-64.62)$ $+-2(0)+3(0)+2(-165.6)=-137.3 \mathrm{kcal} /$ mole of reaction, which makes it highly favorable for the uranium in the basket to react with the $\mathrm{CdCl}_{2}$ and form $\mathrm{UCl}_{3}$ in the salt bath. 
Three days after placing the uranium and $\mathrm{CdCl}_{2}$ in the salt bath, samples were taken from the salt bath and cadmium pool and analyzed at the Material and Fuels Complex in the Analytical Laboratory. Analysis of the cadmium showed no detectable uranium, lithium below its detection limit of $0.0028 \mathrm{wt} \%$ and potassium below its detection limit of $0.007 \mathrm{wt} \%$. The basket contents were not analyzed after the experiment. Table 1 contains the analysis of nine samples taken from the salt bath.

Figure 2 shows the initial conditions in the Mark-IV ER. The two chemical reaction interfaces are the basket-salt interface and the salt-pool interface. The initial species are $U_{\text {metal }}$ in the basket, $\mathrm{LiCl}, \mathrm{KCl}$, and $\mathrm{CdCl}_{2}$ in the salt bath, and liquid cadmium in the pool. The possible final species are elemental $\mathrm{Li}, \mathrm{K}, \mathrm{Cd}$, and $\mathrm{U}$ in the basket, $\mathrm{LiCl}, \mathrm{KCl}, \mathrm{CdCl}_{2}$, and $\mathrm{UCl}_{3}$ in the salt bath, and $\mathrm{Li}$, $\mathrm{K}, \mathrm{Cd}$, and $\mathrm{U}$ in the cadmium pool. Knowing the measured composition of the salt and cadmium, the purpose of this experiment was to determine which free energy minimization method, stoichiometric or non-stoichiometric, was in close agreement with the measurements.

\section{Free Energy Minimization}

In a closed system at a given temperature and pressure, the total Gibbs free energy will decrease

until it reaches a minimum ${ }^{[5]}$. Equation 2 shows the general criterion for chemical equilibrium in a multi-component, multi-phase system.

$$
\mathrm{G}^{\mathrm{t}}=\sum_{a}^{A} \sum_{e}^{E} n_{e a} \mu_{e a}
$$


In equation $2, \mathrm{G}^{\mathrm{t}}$ represents the total Gibbs free energy of all the chemical species, with the terms $n_{e a}$ and $\mu_{e a}$ representing, respectively, the moles and chemical potential of species $e$ in phase $a^{[6]}$. Equation 3 shows the chemical potential for a single species and a species in solution.

$$
\mu_{\mathrm{e}}=\left\{\begin{array}{ll}
\mu_{e a}^{*} & \text { single species, one phase } \\
\mu_{e a}^{*}+\mathrm{R} \ln \left(\frac{\gamma_{e a} n_{e a}}{n_{a}}\right) & \text { multi - species in phase } a
\end{array}\right\}
$$

In equation $3, \mu_{e a}{ }_{e a}$ and $\gamma_{e a}$ are, respectively, the standard state free energy and activity coefficient of species $e$ in phase $a . R$ is the ideal gas constant $(1.987 \mathrm{cal} /$ mole $\mathrm{K})$ and $T$ is the absolute temperature $(773.15 \mathrm{~K})$. The term $n_{a}$ in equation 3 is the total moles $\left(\Sigma n_{e a}\right)$ in phase $a$.

\section{Non-stoichiometric Method}

The non-stoichiometric method determines the $n_{e a}$ values that minimize the total Gibbs free energy in the system subject to the mass balance constraints ${ }^{[7]}$, as shown in equation 4 .

$$
\begin{array}{ll}
\min G^{t}=\sum_{a}^{A} \sum_{e}^{E} n_{e a} \mu_{e a} & \text { subject to : } \\
\sum_{a}^{A} \sum_{e}^{E} z_{\text {mea }} n_{e a}=T_{m} ; & m=1,2, \ldots, M \\
n_{e a} \geq 0 ; & e=1,2, \ldots, E \quad a=1,2, \ldots, A
\end{array}
$$

In equation $4, \mathrm{M}$ is the number of chemical elements in the system. $\mathrm{E}^{*} \mathrm{~A}$ is the number of unique species in the system. For each $n_{\text {ea }}$, the $z_{\text {mea }}$ terms in the $\mathbf{Z}$ matrix (called the formula matrix) represent the number of atoms of chemical element $m$ per atom of $n_{\text {ea }}$. For example, $\mathrm{CdCl}_{2}$ has $z_{\text {mea }}$ values of 1 for the element cadmium and 2 for the element chlorine. $T_{m}$ is the initial amount of moles of the element $m$ and is assumed not to change from initial to final equilibrium 
conditions. For the initial loading of the Mark-IV ER, Table 2 contains the information to minimize the Gibbs free energy with the non-stoichiometric method.

\section{Stoichiometric Method}

The stoichiometric method ${ }^{[8]}$ minimizes the total Gibbs free energy by adjusting the extent of reaction $\left(d \varepsilon_{r}\right)$ incrementally (e.g., Newton-Raphson) for each chemical reaction $r$ and using the $v_{e r}$ terms in the stoichiometric matrix $\mathbf{V}$ to determine the $n_{e}$ values that minimize $\mathrm{G}^{\mathrm{t}}$, as shown in equation 5 .

$$
\begin{aligned}
& \text { Determine } \delta \varepsilon_{r} \text { from }\left(\frac{\partial^{2} \mathrm{G}^{\mathrm{t}}}{\partial \varepsilon_{r}^{2}}\right)_{\mathrm{T}, \mathrm{P}} \cdot \delta \varepsilon_{r}=-\left(\frac{\partial \mathrm{G}^{\mathrm{t}}}{\partial \varepsilon_{r}}\right)_{\mathrm{T}, \mathrm{P}} \text { to obtain } \\
& \left(\frac{\partial \mathrm{G}^{\mathrm{t}}}{\partial \varepsilon_{r}}\right)_{\mathrm{T}, \mathrm{P}}=\sum_{a}^{A} \sum_{e}^{E}\left(v_{e a r} \cdot \mu_{e a}\right)=0 \quad r=1,2, \ldots, R \text { reactions } \\
& \text { where } n_{e a}=n_{e a}+\sum_{r}\left(v_{e a r} \cdot \delta \varepsilon_{r}\right)
\end{aligned}
$$

For a chemical reaction in the form of $v_{a} A+v_{b} B \leftrightarrow v_{c} C+v_{d} D$, the upper-case letters are the chemical species involved in the chemical reaction and the $v$ terms are the stoichiometric coefficients that balance the chemical reaction. For multiple reactions occurring in a system, the stoichiometric coefficients form the stoichiometric matrix $\mathrm{V}$ with a sign convention where $v_{e r}$ is negative for reactants and positive for products. As shown in Figure 2 , the chemical reaction interfaces are the salt-basket interface and the salt-pool interface. Figure 3 shows the independent sets of chemical reactions at these two interfaces and Table 2 contains the initial moles and necessary thermodynamic data. 
Armed with the fundamental knowledge of the two methods and using the initial moles as the starting conditions (initial guess) for the iterations, predictions from both were compared to the sample analysis.

\section{RESULTS}

For the non-stoichiometric method, the Solver ${ }^{\circledR}$ function ${ }^{[9]}$ in Microsoft Excel ${ }^{\circledR}$ converged and satisfied the constraints. The total Gibbs free energy went from an initial value of $-435619 \mathrm{kcal}$ to $-435670 \mathrm{kcal}$. The stoichiometric method used the Newton-Raphson iteration method to minimize the Gibbs free energy by adjusting the extents of reaction. The total Gibbs free energy went from $-435619 \mathrm{kcal}$ (initial value) to $-439005 \mathrm{kcal}$. Table 3 compares the salt and cadmium sample analysis to their initial compositions and the compositions predicted via the two chemical equilibrium methods. Figure 4 is a graph of the initial and final salt compositions.

Both Table 3 and Figure 4 show that the stoichiometric method predicted a salt composition in agreement with the measured results where the non-stoichiometric method did not.

A possible explanation for this disparity is the geometry of the Mark-IV electrorefiner. Normally, the formula matrix $\mathbf{Z}$, used in the non-stoichiometric method, is closely related to the stoichiometric matrix $\mathbf{V}$, used in the stoichiometric method, by the relationship $\mathbf{Z V}=\mathbf{0}^{[10]}$ with the number of chemical reactions $(R)$ equal to the number of possible species $\left(E^{*} A\right)$ minus the number of elements $(M)$, or $R=E A-M$. Using the formula matrix $\mathbf{Z}$ in Table 2 , the stoichiometric matrix satisfying the equation $\mathbf{Z V}=0$ is shown in Table 4 and the corresponding chemical reactions shown in Figure 5. 
But the two metal phases (basket and cadmium pool) in the Mark-IV ER are only in contact with the salt and not in contact with each other. Figure 5 shows chemical reactions between the basket and the cadmium pool, which is a phase boundary that does not exist in the Mark-IV ER. Therefore, the formula matrix $Z$ in Table 2 (used in the non-stoichiometric method) and the relationship $Z V=0$ does not create a stoichiometric matrix V that represents the chemical reactions occurring in the Mark-IV ER, as seen when comparing

Figure 3 and Figure 5. Because the stoichiometric method uses a set of chemical reactions that better represents what is occurring in the Mark-IV ER, there is more confidence in its final equilibrium composition than the non-stoichiometric method. Regardless, the purpose of the experiment was to compare the two methods of minimizing the Gibbs free energy and to determine which one would produce results that agreed with the measurements. At present and until further study shows otherwise, the stoichiometric method predicted an equilibrium composition in the initial Mark-IV ER loading that agreed with the measured composition. Future work will investigate how the electrorefiner process model handles more complex systems (e.g., the minor constituents in spent nuclear fuel and isotopes).

\section{CONCLUSIONS}

Predicting the electrorefiner inventory allows for continuing spent fuel treatment without waiting for sample analysis. To this end, an electrorefiner process model required a method to perform multi-component, multi-phase chemical equilibrium. Two chemical equilibrium methods, 
stoichiometric and non-stoichiometric, were investigated for the initial loading of the Mark-IV electrorefiner to determine which method would predict an equilibrium composition that agreed with the measured salt composition. Minimizing the Gibbs free energy using extents of reaction (the stoichiometric method) produced an equilibrium composition in the salt bath in agreement with the measured values whereas using mass balance constraints (the non-stoichiometric method) did not. Because of the geometry of the Mark-IV electrorefiner, where the metal phases are only in contact with the salt phase, the stoichiometric method can better represent the chemical reactions occurring at the phase boundaries where the non-stoichiometric method may not represent the chemical reactions occurring in the Mark-IV ER. 
Table 1. Salt Sample Analysis after Oxidizing Uranium to $\mathrm{UCl}_{3}$ Using $\mathbf{C d C l}_{2}$

\begin{tabular}{|c|c|c|c|c|}
\hline Sample ID & $\begin{array}{c}\mathrm{g} \mathrm{Li}(\text { as LiCl) } \\
\text { per 100 g Salt }\end{array}$ & $\begin{array}{c}\mathrm{g} \mathrm{K}(\text { as KCl) } \\
\text { per } 100 \mathrm{~g} \text { Salt }\end{array}$ & $\begin{array}{c}\mathrm{g} \mathrm{Cd}\left(\mathrm{as} \mathrm{CdCl}_{2}\right) \\
\text { per 100 g Salt }\end{array}$ & $\begin{array}{c}\mathrm{g} \mathrm{U}\left(\mathrm{as} \mathrm{UCl}_{3}\right) \\
\text { per } 100 \mathrm{~g} \mathrm{Salt}\end{array}$ \\
\hline SAMB20 & 6.0 & 26.1 & 0.01 & 4.26 \\
\hline SAMB18 & 6.0 & 26.4 & No analysis & 4.27 \\
\hline SAMB29 & 5.8 & 26.0 & 0.01 & 4.26 \\
\hline SAMB13 & 5.1 & 26.0 & 0.04 & 4.21 \\
\hline SAMB10 & 5.9 & 26.8 & 0.01 & 4.28 \\
\hline SAMB09 & 5.8 & 26.3 & 0.02 & 4.28 \\
\hline SAMB06 & 6.5 & 25.0 & 0.00 & 4.28 \\
\hline SAMB05 & 7.2 & 26.0 & 0.03 & 4.27 \\
\hline SAMB04 & 6.6 & 27.1 & 0.01 & 4.28 \\
\hline Average & 6.1 & 26.2 & 0.01 & 4.27 \\
\hline 20 & 1.2 & 1.2 & 0.02 & 0.04 \\
\hline
\end{tabular}

a $2 \sigma=$ twice the standard deviation of the measured data or $95 \%$ confidence interval

Table 2. Information to Minimize Gibbs Free Energy via Non-Stoichiometric Methods

\begin{tabular}{|c|c|c|c|c|c|c|c|c|}
\hline \multirow[b]{2}{*}{ Species $(E A=12)$} & \multicolumn{6}{|c|}{ Chemical Elements $(M=5) \& \mathbf{Z}$ Matrix } & \multirow[b]{2}{*}{$\mu_{e}^{*}{ }^{a}$} & \multirow[b]{2}{*}{$\gamma_{e}{ }^{b}$} \\
\hline & $\mathrm{Li}$ & $\mathrm{K}$ & $\mathrm{Cd}$ & $\mathrm{U}$ & $\mathrm{Cl}$ & $\begin{array}{l}\text { Initial } \\
\text { Moles }\end{array}$ & & \\
\hline Li (basket) & 1 & & & & & & 0 & \\
\hline $\mathrm{K}$ (basket) & & 1 & & & & & 0 & \\
\hline Cd (basket) & & & 1 & & & & 0 & \\
\hline U (basket) & & & & 1 & & 84.08 & 0 & \\
\hline $\mathrm{LiCl}$ (salt) & 1 & & & & 1 & 4601.4 & -82.46 & 0.892 \\
\hline $\mathrm{KCl}$ (salt) & & 1 & & & 1 & 3159.2 & -86.63 & 1.655 \\
\hline $\mathrm{CdCl}_{2}$ (salt) & & & 1 & & 2 & 126.4 & -64.62 & 0.0662 \\
\hline $\mathrm{UCl}_{3}$ (salt) & & & & 1 & 3 & & -165.6 & 0.169 \\
\hline $\mathrm{Li}($ pool) & 1 & & & & & & 0 & 0.0018 \\
\hline K (pool) & & 1 & & & & & 0 & 5 \\
\hline $\mathrm{Cd}$ (pool) & & & 1 & & & 4720.4 & 0 & 1 \\
\hline $\mathrm{U}($ pool) & & & & 1 & & & 0 & 88.73 \\
\hline Total Moles $\left(T_{m}\right)$ & 4601.4 & 3159.2 & 4846.8 & 84.08 & 8013.4 & & & \\
\hline
\end{tabular}


Table 3. Comparison of Modeling Methods to Measured Results

\begin{tabular}{|c|c|c|c|c|c|}
\hline & $\begin{array}{c}\text { Initial } \\
\text { Values }\end{array}$ & $\begin{array}{c}\text { Final Values } \\
\text { Stoichiometric } \\
\text { Method }\end{array}$ & $\begin{array}{c}\text { Final Values } \\
\text { Non-stoichiometric } \\
\text { Results }\end{array}$ & $\begin{array}{c}\text { Sample } \\
\text { Analysis } \\
\text { (Average) }\end{array}$ & $\begin{array}{c}95 \% \\
\text { confidence } \\
\text { interval }\end{array}$ \\
\hline $\mathrm{wt}^{2} \mathrm{Li}$ (as LiCl) & 7.04 & 6.95 & 7.0 & 6.1 & 1.2 \\
\hline $\mathrm{wt} \% \mathrm{~K}$ (as $\mathrm{KCl})$ & 27.22 & 26.88 & 27.2 & 26.2 & 1.2 \\
\hline $\mathrm{wt} \% \mathrm{Cd}\left(\right.$ as $\mathrm{CdCl}_{2}$ ) & 3.13 & 0.01 & 3.13 & 0.01 & 0.02 \\
\hline $\mathrm{wt} \% \mathrm{U}\left(\right.$ as $\left.\mathrm{UCl}_{3}\right)$ & 0.00 & 4.35 & 0.01 & 4.27 & 0.04 \\
\hline $\mathrm{wt} \% \mathrm{Li}$ in Cd Pool & 0.0 & 0.0 & 0.0 & $<0.0028$ & NA \\
\hline wt $\% \mathrm{~K}$ in Cd Pool & 0.0 & 0.0 & 0.0 & $<0.007$ & NA \\
\hline $\mathrm{wt} \% \mathrm{Cd}$ in $\mathrm{Cd}$ Pool & 100 & 100 & 100 & 100 & NA \\
\hline wt\% U in Cd Pool & 0.0 & 0.0 & 0.0 & 0 & NA \\
\hline
\end{tabular}

Table 4. Stoichiometric Matrix Derived from Non-stoichiometric Formula Matrix

\begin{tabular}{|c||c|c|c|c||c|c|c|c|c||c|c|c||}
\hline \multicolumn{1}{|c||}{} & \multicolumn{5}{c||}{ Basket } & \multicolumn{5}{c||}{ Salt } & \multicolumn{3}{c||}{ Cd Pool } \\
\hline Reaction & $\mathrm{Li}$ & $\mathrm{K}$ & $\mathrm{Cd}$ & $\mathrm{U}$ & $\mathrm{LiCl}$ & $\mathrm{KCl}$ & $\mathrm{CdCl}_{2}$ & $\mathrm{UCl}_{3}$ & $\mathrm{Li}$ & $\mathrm{K}$ & $\mathrm{Cd}$ & $\mathrm{U}$ \\
\hline 1 & 1 & -1 & & & -1 & 1 & & & & & & \\
\hline 2 & 2 & & -1 & & -2 & & 1 & & & & & \\
\hline 3 & 3 & & & -1 & -3 & & & 1 & & & & \\
\hline 4 & -1 & & & & & & & & 1 & & & \\
\hline 5 & & -1 & & & & & & & & 1 & & \\
\hline 6 & & & -1 & & & & & & & & 1 & \\
\hline 7 & & & & -1 & & & & & & & & 1 \\
\hline
\end{tabular}




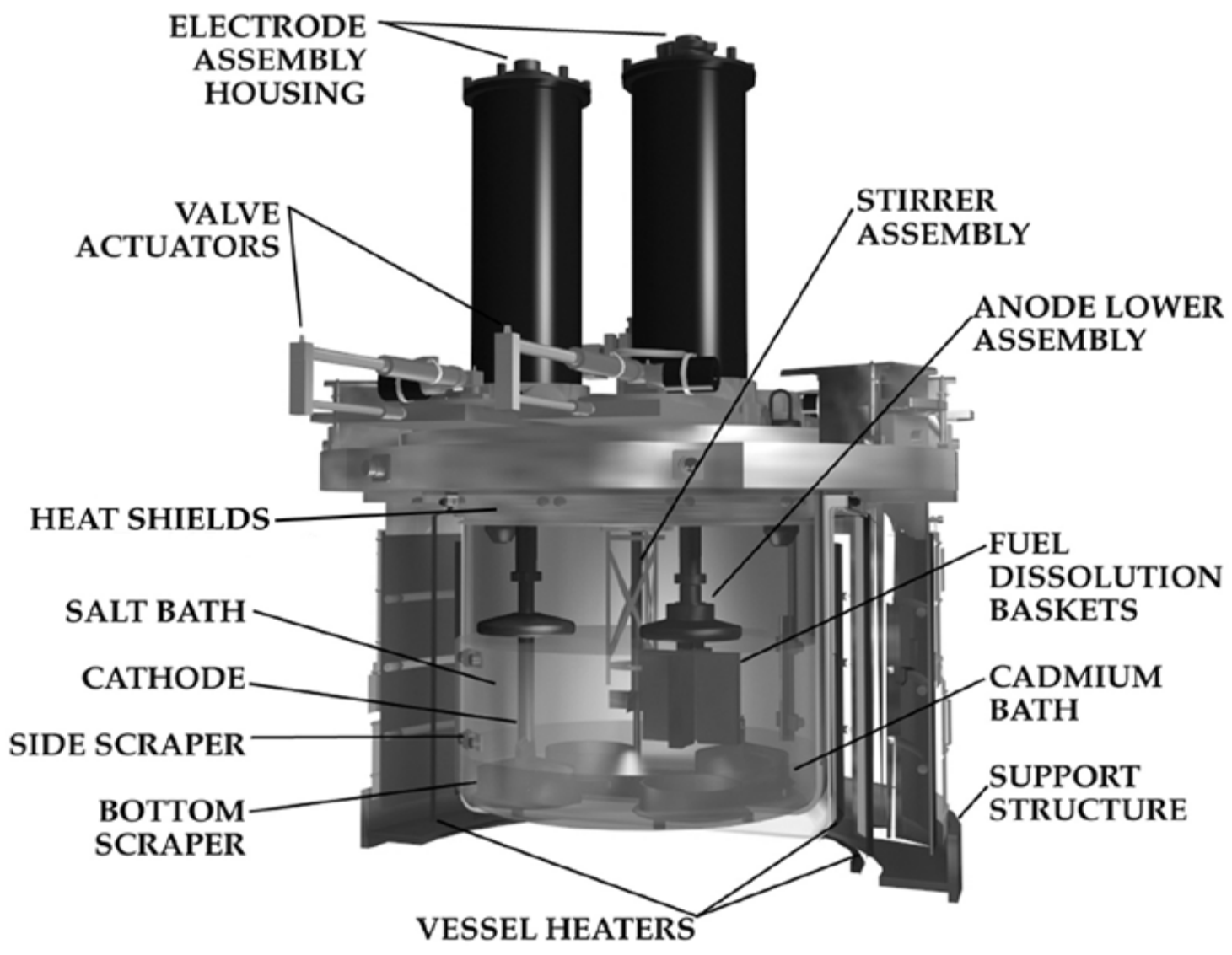

Figure 1. Mark-IV Electrorefiner 


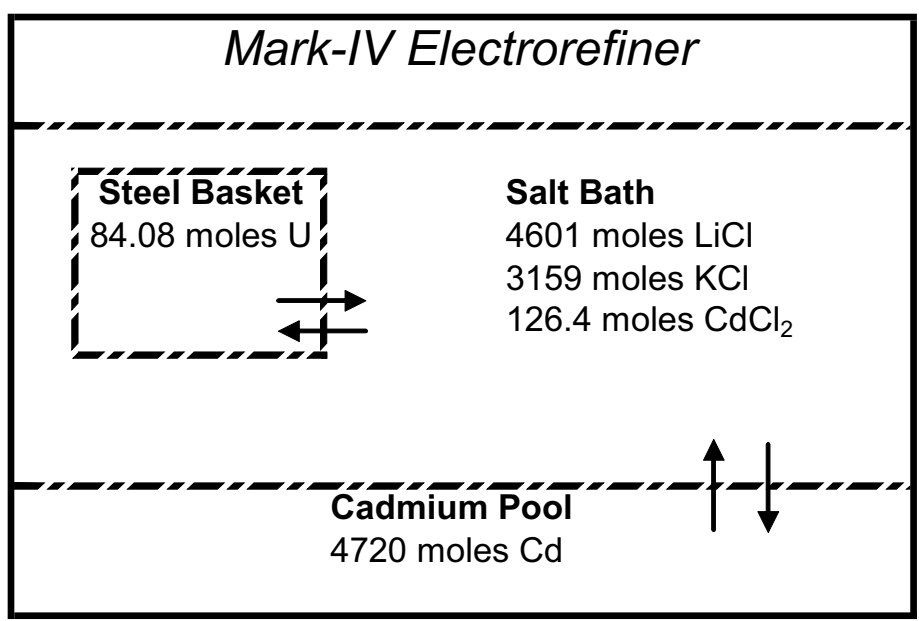

Figure 2. Schematic Showing Initial Conditions in Mark-IV Electrorefiner 


$\left[\begin{array}{c}\text { Salt - Basket Reactions } \\ 3 \mathrm{LiCl}+U_{\text {basket }} \leftrightarrow 3 \mathrm{Li}_{\text {basket }}+U \mathrm{Ul}_{3} \\ 3 \mathrm{KCl}+U_{\text {basket }} \leftrightarrow 3 \mathrm{~K}_{\text {basket }}+U \mathrm{Ul}_{3} \\ 3 \mathrm{CdCl}+2 \mathrm{U}_{\text {basket }} \leftrightarrow 3 \mathrm{Cd}_{\text {basket }}+2 \mathrm{UCl}_{3}\end{array}\right]\left[\begin{array}{c}\text { Salt - Cd Pool Reactions } \\ 2 \mathrm{LiCl}+\mathrm{Cd}_{\text {pool }} \leftrightarrow 2 \mathrm{Li}_{\text {pool }}+\mathrm{CdCl}_{2} \\ 2 \mathrm{KCl}+\mathrm{Cd} d_{\text {pool }} \leftrightarrow 2 \mathrm{~K}_{\text {pool }}+\mathrm{CdCl}_{2} \\ 2 U C l_{3}+3 \mathrm{Cd} d_{\text {pool }} \leftrightarrow 2 U_{\text {pool }}+3 \mathrm{CdCl}_{2}\end{array}\right]$

Figure 3. Chemical Reactions at Phase Boundaries in Mark-IV Electrorefiner 


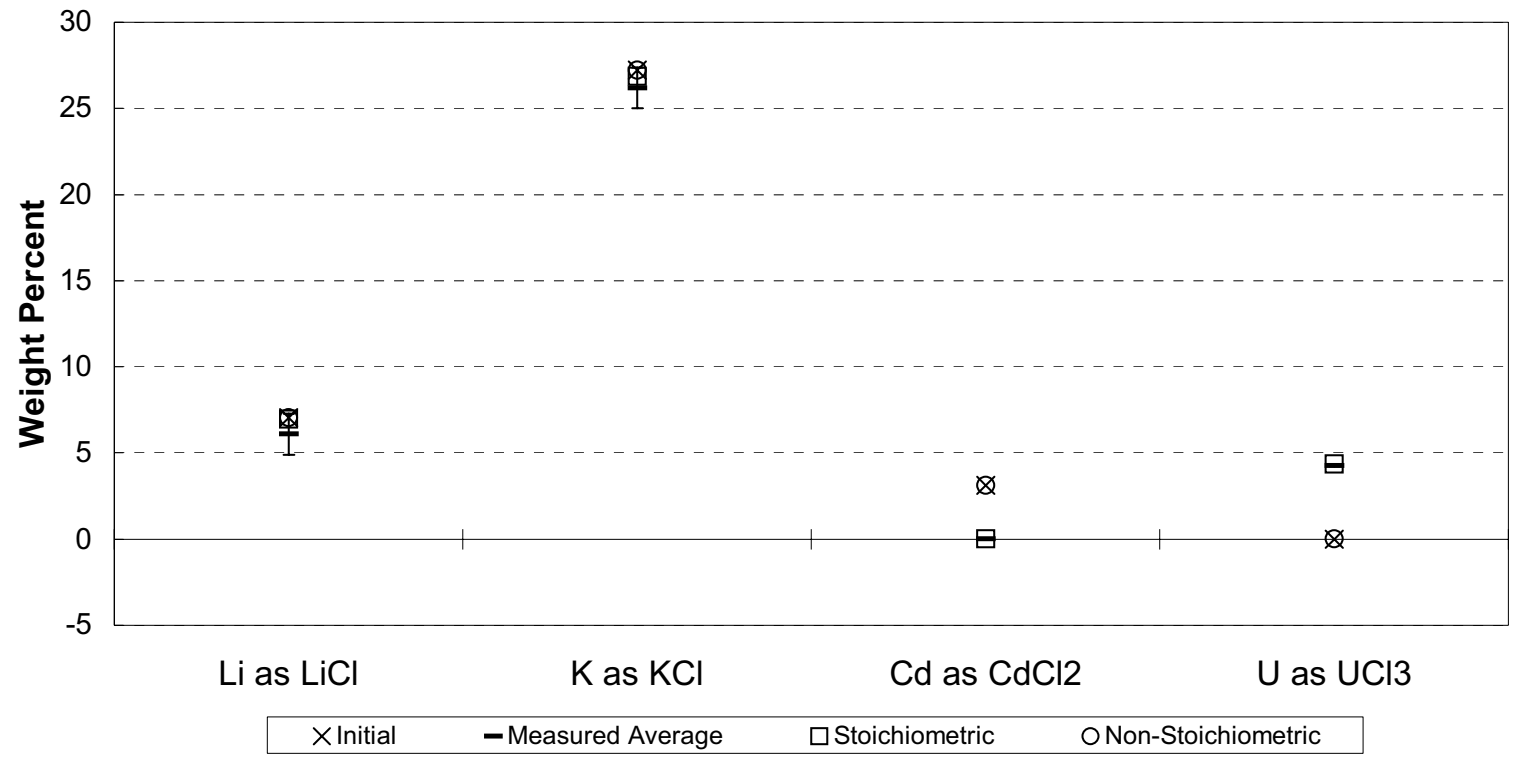

Figure 4. Measured and Predicted Mark-IV ER Composition - Initial Loading 


$$
\left[\begin{array}{c}
\text { Salt - Basket Reactions } \\
L i C l+K_{\text {basket }} \leftrightarrow L i_{\text {basket }}+K C l \\
2 L i C l+C d_{\text {basket }} \leftrightarrow 2 L i_{\text {basket }}+C d C l_{2} \\
3 L i C l+U_{\text {basket }} \leftrightarrow 3 L i_{\text {basket }}+U C l_{3}
\end{array}\right]\left[\begin{array}{c}
\text { Basket - Pool Reactions } \\
L i_{\text {basket }} \leftrightarrow L i_{\text {pool }} \\
K_{\text {basket }} \leftrightarrow K_{\text {pool }} \\
C d_{\text {basket }} \leftrightarrow C d_{\text {pool }} \\
U_{\text {basket }} \leftrightarrow U_{\text {pool }}
\end{array}\right]
$$

Figure 5. Independent Set of Chemical Reactions 


\section{REFERENCES}

$1 \quad$ Laidler, J.J., Pyrochemical Processing of DOE Spent Nuclear Fuel, Proceedings of DOE Spent Nuclear Fuel Challenges and Initiatives, Salt Lake City, Utah, December 13-16, 1994.

2 Goff, K.M., Benedict, R.W., Johnson, S.G., Mariani, R.D., Simpson, M.F., Westphal, B.R., Electrometallurgical Treatment Demonstration at ANL-West, presented at American Nuclear Society Embedded Topical Meeting Spent Fuel and Fissile Material, June 2000.

3 Smith, W.R., and Missen, R.W., 1991, Chemical Reaction Equilibrium Analysis: Theory and Algorithms: Malibar, Florida, Krieger Publishing Company, 364 p.

4 Barin, I., Thermodynamic Data of Pure Substances, VCH, Weinheim, NY, 1992.

5 J.M. Smith, H.C. Van Ness (1975), Introduction to Chemical Engineering Thermodynamics, McGraw-Hill, p. 293.

$6 \quad$ W.R. Smith, R.W. Missen (1982), Chemical Reaction Equilibrium Analysis, Wiley, p. 43.

7 J.M. Smith, H.C. Van Ness (1975), Introduction to Chemical Engineering Thermodynamics, McGraw-Hill, pp. 424-428.

$8 \quad$ V.C. Kress, On the Mathematics of Associated Solutions, American Journal of Science, Volume 303, October 2003. p. 713.

9 Microsoft Excel Solver uses the Generalized Reduced Gradient (GRG2) nonlinear optimization code developed by Leon Lasdon, University of Texas at Austin, and Allan Waren, Cleveland State University, Frontline Systems, Inc., P.O. Box 4288, Incline Village, NV 89450-4288, (702) 831-0300, Web site:

http://www.frontsys.com, Electronic mail: info@frontsys.com

10 V.C. Kress, On the Mathematics of Associated Solutions, American Journal of Science, Volume 303, October 2003. p. 713.

11 Barin, I., Thermodynamic Data of Pure Substances, VCH, Weinheim, NY, 1992.

12 Plambeck, J.A., Encyclopedia of Electrochemistry of the Elements, Volume X, Fused Salt Systems, Bard, A.J. (Ed), Chapter 2, Marcel Dekker, N.Y., 1976. 